\title{
A New Protocol to Discover Novel Anti-Aging Compounds
}

Fumiaki Uchiumi ${ }^{1,2^{*}}$, Takahiro Oyama ${ }^{1}$, Kensuke Ozaki ${ }^{1}$, Megumi Fukui $^{1}$, Hisui Ogawa ${ }^{1}$, Yuki Sasaki ${ }^{1}$, Haruki Tachibana ${ }^{3}$, Chisato

Fukushima ${ }^{3}$, Makoto Fujikawa ${ }^{3}$, Hideaki Abe ${ }^{4}$, Steven Larsen² and Sei-ichi Tanuma ${ }^{2,3}$

${ }^{1}$ Department of Gene Regulation, Faculty of Pharmaceutical Sciences, Tokyo University of Science, Noda-shi, Chiba-ken, Japan

${ }^{2}$ Research Center for RNA Science, RIST, Tokyo University of Science, Noda-shi, Chiba-ken, Japan

${ }^{3}$ Biochemistry, Faculty of Pharmaceutical Sciences, Tokyo University of Science, Noda-shi, Chiba-ken, Japan

${ }^{4}$ Hinoki Shinyaku Co., Ltd, 9-6 Nibancho, Chiyoda-ku, Tokyo 102-0084, Japan

\begin{abstract}
Several natural and chemical compounds have been suggested to have effects as anti-aging drugs. For example, caloric restriction (CR) mimetics trans-resveratrol (Rsv) and 2-deoxy-D-glucose (2DG) are candidate compounds that can elongate life span of organisms, and they might also have roles in the regulation of telomere maintenance and mitochondrial functions. Recently, pharmaceutical medicaments rapamycin, an immunosuppressant and metformin, a medicine for diabetes, have been shown to act on the insulin/IGF1 signaling pathway. Therefore, they are also expected to have anti-aging effects. Here we propose a new protocol to discover novel compounds that can be used as a remedy to slow senescence and control aging in the aspect of promoter activities of telomere and energy metabolism-regulating factor encoding genes.
\end{abstract}

Keywords: Caloric restriction; Cellular senescence; 2-deoxy-Dglucose; Lignin carbohydrate complex; Metformin; Oxidative stress; Rapamycin; Resveratrol

\section{Introduction}

All living things are exposed to various stresses throughout their life span, including sun light, radiation, natural and chemical compounds, viruses, and other stimuli that cause damage to cellular DNA. Protection of chromosomes from various damages is critical requirement for organisms, because aging is thought to be caused by accumulation of damage at the chromosomes [1].

It has been shown that telomere-shortening accelerates cellular senescence, and that protection of telomeres from DNA replication process and/or DNA-damage is necessary to keep chromosomal integrity $[2,3]$. Therefore, induction of telomere-maintenance mechanisms should be applied for anti-aging therapy. One such target for anti-aging therapy might be LMNA, in which a loss of function mutation is known to cause Hutchison-Gilford progeria syndrome (HGPS) [4]. The LMNA gene encodes lamin A protein, an essential structural component of the nuclear membrane [5]. Telomeres are thought to be heterochromatic and associate with nuclear matrix membrane via heterochromatin protein 1 (HP1) [6]. Therefore, HGPS could be partly explained by disruption of telomere maintenance.

Another aspect of aging is that life span of organisms is regulated by the reactive oxygen species (ROS) and energy stresses that are associated with mitochondrial functions $[7,8]$. Recently, it was shown that telomere dysfunction affects mitochondria, where ROS are mainly generated, via p53 mediated suppression of peroxisome proliferatoractivated receptor gamma, coactivator 1 alpha (PGC-1 $\alpha$ ) [9]. It should also be noted that the tumor suppressor protein $\mathrm{p} 53$ regulates mitochondrial functions including respiration and glycolysis $[10,11]$.

Recent studies have shown that the sirtuin (SIRT) protein family, comprising of SIRT1-SIRT7, plays important roles in controlling metabolism and health span [12]. Among these, SIRT1, an NAD ${ }^{+}$ dependent deacetylating enzyme, has been widely known to act on glucose metabolism by modulating functions of various targets including PGC-1a, FOXO1, p53, HIF1a, UCP2, and other proteins [12]. Growth hormone $(\mathrm{GH})$ resistance and deficiency of GH increase longevity of mice [13], suggesting that the signals induced by the action of GH on IGF-1, which belongs to the insulin signaling system, affects aging of organisms [14]. Moreover, GH does not only regulate IGF1 , but also stimulates secretion of insulin [14]. Genetic studies in $C$. elegans, Drosophila and mice showed that the insulin signaling system plays important roles in determining life span of the organisms [15]. Considering that mTOR and AMPK are key proteins in the insulin signaling pathways, these lines of evidences strongly suggest that these gene products could be attractive targets for anti-aging therapies [16].

Taken together, the biological factors involved in determination of life span may be categorized into several groups, telomere metabolism, ROS and mitochondrial functions, and insulin signaling system.

\section{Analytical Methods}

Our previous studies demonstrated that caloric restriction (CR) mimetic compounds, such as 2-deoxy-D-glucose (2DG) and transresveratrol (Rsv) moderately enhance telomerase activity along with induction of WRN gene expression in HeLa S3 cells [17,18]. Luciferasereporter transfection experiments showed that these CR mimetic compounds up-regulate relative promoter activities of the 5 -upstream regions of human telomere-associated proteins and shelterin-encoding genes when compared with that of the PIF1 gene [19]. The PIF1 encodes a protein containing homology with a Rec D type DNA helicase that negatively regulate telomere length $[20,21]$. Furthermore, by using these relative values, we observed that $\beta$-thujaplicin (hinokitiol) has similar effects on promoter activities of these genes [22]. We also found that not only Rsv, but also pine cone lignin carbohydrate complex (LLC)

*Corresponding author: Fumiaki Uchiumi, Ph.D., Department of Gene Regulation Faculty of Pharmaceutical Sciences, Tokyo University of Science, 2641 Yamazaki, Noda-shi, Chiba-ken 278-8510, Japan, Tel: +81-4-7121-3616; Fax: +81-4-7121 3608; E-mail: uchiumi@rs.noda.tus.ac.jp

Received September 28, 2012; Accepted October 08, 2012; Published October 12, 2012

Citation: Uchiumi F, Oyama T, Ozaki K, Fukui M, Ogawa H, et al. (2012) A New Protocol to Discover Novel Anti-Aging Compounds. Pharmaceut Anal Acta 3:166. doi:10.4172/2153-2435.1000166

Copyright: @ 2012 Uchiumi F, et al. This is an open-access article distributed unde the terms of the Creative Commons Attribution License, which permits unrestricted use, distribution, and reproduction in any medium, provided the original author and source are credited. 


\begin{tabular}{|l|c|c|}
\hline Compound & Relative TMAE & Reference \\
\hline Rsv $(10 \mu \mathrm{M})$ & 1.399 & {$[19]$} \\
\hline 2DG $(4 \mathrm{mM})$ & 4.115 & {$[19]$} \\
\hline 2DG $(8 \mathrm{mM})$ & 2.804 & {$[19]$} \\
\hline$\beta$-thujaplicin $(10 \mu \mathrm{M})$ & 2.078 & {$[22]$} \\
\hline Rapamycin $(1 \mu \mathrm{M})$ & 1.256 & unpublished \\
\hline
\end{tabular}

\section{Relative $\mathrm{TME}=\mathrm{TME}_{(\mathrm{CR} \text { mimetics }} / \mathrm{TME}_{\text {con }}$}

Here, each constant was set as $\mathrm{k}_{1}=\mathrm{k}_{2}=\mathrm{k}_{3}=\ldots=\mathrm{k}_{\mathrm{N}}=1$.

Table 1: TME value in HeLa S3 cells.

and $\beta$-thujaplicin up-regulate human SIRT1 promoter activity, these have already been reported to have favorable effects on mammalian cells [22-25]. Thus, we propose that the anti-aging effects of natural and synthetic compounds could be easily screened by the promoter activity ratios of the SIRT1 and telomere-maintenance factor encoding genes normalized with that of the PIF1.

Based on these observations, the formula that indicates telomeremaintenance associated anti-aging effect (TME) of a specific compound A will be given as follows:

$$
\begin{aligned}
& \operatorname{TME}_{\mathrm{A}}=\left(\mathrm{k}_{1}\left[\text { gene } \mathrm{x}_{1}\right]_{\mathrm{p}}+\mathrm{k}_{2}\left[\text { gene } \mathrm{x}_{2}\right]_{\mathrm{p}}+\mathrm{k}_{3}\left[\text { gene } \mathrm{x}_{3}\right]_{\mathrm{p}} \ldots+\mathrm{k}_{\mathrm{N}}\left[\text { gene } \mathrm{x}_{\mathrm{N}}\right]_{\mathrm{p}}\right) / \\
& \left(\left[P I F_{1}\right]_{\mathrm{p}} \mathrm{xN}\right) \\
& \mathrm{k}_{1}+\mathrm{k}_{2}+\mathrm{k}_{3}+\ldots+\mathrm{k}_{\mathrm{N}}=\mathrm{N}
\end{aligned}
$$

In this formula, genes $x_{1}$ to $x_{N}$ encode telomere maintenance factors, and [gene $\left.x_{1}\right]_{p}$ and $k_{1}$ represent promoter activities of gene $x_{1}$, and contribution constant of $\left[\text { gene } \mathrm{x}_{1}\right]_{\mathrm{p}}$.

\section{Results}

At present, constant $\mathrm{k}_{1}$ to $\mathrm{k}_{\mathrm{N}}$ is unknown. Therefore, tentatively all constants were set equally at 1 . Then TME values of Rsv $(10 \mu \mathrm{M}), 2-\mathrm{DG}$ ( $4 \mathrm{mM}$ and $8 \mathrm{mM})$, and $\beta$-thujaplicin $(10 \mu \mathrm{M})$ were estimated from the previous results $[19,22]$. Table 1 shows the TME values of these CR mimetic compounds are over 1.00 in HeLa S3 cells. The result suggests that this estimation could be useful to predict the efficacy of anti-aging drugs, when applied to the analysis of promoter activities for telomere maintenance factor encoding genes. It is widely known that p53mediated cellular responses are generated from its cellular levels and phosphorylation, which are mainly post-transcriptionally regulated. However, we propose here that evaluation of the TP53 gene expression could be also included in the above formula. Because increased p53 protein level may affect cell proliferation, which is also a feature of cellular senescence, inducing not only cell cycle check point-associated genes but also suppressing expression of mitochondrial functionregulatory gene $P G C-1 \alpha[9]$.

\section{Discussion}

Rapamycin and metformin, which are known to inhibit mTOR and activate AMPK, respectively, could be lead compounds that might retard aging [26]. Although these two drugs are regarded as CR mimetics, the molecular mechanism, through which they extend life span, is thought to be different from that of Rsv, 2DG and LLC. That is, rapamycin negatively regulates telomere length in yeast [27] and telomerase in human cells [28]. To present, there is no report that shows the effect of metformin on telomeres. These observations imply that extension of life span is not defined solely by telomere and telomerase regulation. Although we are proposing that the balance between telomere elongation/maintenance and its shortening-inducing signals will be useful to find anti-aging compounds, there should be other mechanisms that determine senescence and aging in a telomere/ telomerase-independent manner.

\section{References}

1. Vijg J (2007) Genome instability and accelerated aging. In: Aging of the Genome: The Dual Role of DNA in Life and Death, Oxford University Press, NY: 151-180.

2. Blackburn E (2006) Chapter 1: A history of telomere biology. In: Telomeres (2 $2^{\text {nd }}$ edn), Cold Spring Harbor Laboratory Press, NY: 1-19.

3. O'Sullivan RJ, Karlseder J (2010) Telomeres: protecting chromosomes against genome instability. Nat Rev Mol Cell Biol 11: 171-181.

4. Eriksson M, Brown WT, Gordon LB, Glynn MW, Singer J, et al. (2003) Recurrent de novo point mutations in lamin A cause Hutchinson-Gilford progeria syndrome. Nature 423: 293-298.

5. Oberdoerffer P, Sinclair DA (2007) The role of nuclear architecture in genomic instability and ageing. Nat Rev Mol Cell Biol 8: 692-702.

6. Sharma GG, Hwang KK, Pandita RK, Gupta A, Dhar S, et al. (2003) Human heterochromatin protein 1 isoforms HP1(Hsalpha) and HP1(Hsbeta) interfere with hTERT-telomere interactions and correlate with changes in cell growth and response to ionizing radiation. Mol Cell Biol 23: 8363-8376.

7. Benz CC, Yau C (2008) Ageing, oxidative stress and cancer: paradigms in parallax. Nat Rev Cancer 8: 875-879.

8. Robb EL, Page MM, Stuart JA (2009) Mitochondria, cellular stress resistance, somatic cell depletion and lifespan. Curr Aging Sci 2: 12-27.

9. Sahin E, Colla S, Liesa M, Moslehi J, Müller FL, et al. (2011) Telomere dysfunction induces metabolic and mitochondrial compromise. Nature 470: 359-365.

10. Matoba S, Kang JG, Patino WD, Wragg A, Boehm M, et al. (2006) p53 regulates mitochondrial respiration. Science 312: 1650-1653.

11. Bensaad K, Tsuruta A, Selak MA, Vidal MN, Nakano K, et al. (2006) TIGAR, a p53-inducible regulator of glycolysis and apoptosis. Cell 126: 107-120.

12. Houtkooper RH, Pirinen E, Auwerx J (2012) Sirtuins as regulators of metabolism and healthspan. Nat Rev Mol Cell Biol 13: 225-238.

13. Russel SJ, Kahn CR (2007) Endocrine regulation of ageing. Nat Rev Mol Cell Biol 8: 681-691.

14. Bartke A (2011) Growth hormone, insulin and aging: The benefits of endocrine defects. Exp Gerontol 46: 108-111.

15. Kenyon CJ (2010) The genetics of ageing. Nature 464: 504-512.

16. Zoncu R, Efeyan A, Sabatini DM (2011) mTOR: from growth signal integration to cancer, diabetes and aging. Nat Rev Mol Cell Biol 12: 21-35

17. Zhou B, Ikejima T, Watanabe T, Iwakoshi K, Idei Y, et al. (2009) The effect of 2-deoxy-D-glucose on Werner syndrome RecQ helicase gene. FEBS Lett 583 1331-1336.

18. Uchiumi F, Watanabe T, Hasegawa S, Hoshi T, Higami Y, et al. (2011) The effect of resveratrol on the Werner syndrome RecQ helicase gene and telomerase activity. Curr Aging Sci 4: 1-7

19. Uchiumi F, Oyama T, Ozaki K, Tanuma S (2011) Chapter 29: Characterization of 5'-flanking regions of various human telomere maintenance factor-encoding genes. In: DNA Repair (Kruman I, Ed.), InTech-Open Access Publisher, Inc, Rijeka, Croatia: 585-596.

20. Zhang DH, Zhou B, Huang Y, Xu LX, Zhou JQ (2006) The human Pif1 helicase, a potential Escherichia coli RecD homologue, inhibits telomerase activity. Nucleic Acids Res 34: 1393-1404.

21. Chang M, Luke B, Kraft C, Li Z, Peter M, et al. (2009) Telomerase is essential to alleviate Pif1-induced replication stress at telomeres. Genetics 183: 779-791.

22. Uchiumi F, Tachibana H, Abe H, Yoshimori A, Kamiya T, et al. (2012) Effects of thujaplicins on the promoter activities of the human SIRT1 and telomere maintenance factor encoding genes. Pharmaceut Anal Acta 3: 159.

23. Uchiumi F, Tachibana H, Larsen S, Tanuma S (2012) Effect of lignin glycosides extracted from pine cones on the human SIRT1 promoter. Pharmaceut Ana Acta S8: 001. 
Citation: Uchiumi F, Oyama T, Ozaki K, Fukui M, Ogawa H, et al. (2012) A New Protocol to Discover Novel Anti-Aging Compounds. Pharmaceut Anal Acta 3:166. doi:10.4172/2153-2435.1000166

Page 3 of 3

24. Harada H, Sakagami H, Konno K, Sato T, Osawa N, et al. (1988) Induction of antimicrobial activity by antitumor substances from pine cone extract of Pinus parviflora Sieb. et Zucc. Anticancer Res 8: 581-587.

25. Sakagami H, Kawazoe Y, Oh-hara T, Kitajima K, Inoue Y, et al. (1991) Stimulation of human peripheral blood polymorphonuclear cell iodination by lignin-related substances. J Leukoc Biol 49: 277-282.

26. Mouchiroud L, Molin L, Dallière N, Solari F (2010) Life span extension by resveratrol, rapamycin, and metformin: The promise of dietary restriction mimetics for an healthy aging. Biofactors 36: 377-382.

27. Ungar L, Harari Y, Toren A, Kupiec M (2011) Tor complex 1 controls telomere length by affecting the level of Ku. Curr Biol 21: 2115-2120.

28. Chebel A, Rouault JP, Urbanowicz I, Baseggio L, Chien WW, et al. (2009) Transcriptional activation of $h T E R T$, the human telomerase reverse transcriptase, by nuclear factor of activated T cells. J Biol Chem 284: 35725-35734. 